\title{
Asymmetric behavior of magnetic dip poles
}

\author{
M. Mandea and E. Dormy \\ Institut de Physique du Globe de Paris, 4 place Jussieu, 75252 Paris Cedex 05, France \\ (Received November 8, 2002; Revised February 3, 2003; Accepted March 3, 2003)
}

\begin{abstract}
The north magnetic dip pole velocity has more than doubled in the last 30 years. This observation, together with the decrease in the Earth's magnetic dipole intensity over the last century has raised the concern of a possible approaching polarity reversal. We show that this rapid variation is in fact to be expected, and will not affect the dipolar field as a whole, but only the north magnetic pole. We demonstrate how this rapid displacement of the north magnetic pole is made possible by the horizontal field morphology. This rapid variation of north magnetic pole position does not imply any important modification of the core processes associated with field generation. The north magnetic pole position being very sensitive to small as well as rapid variations of the field, we show that it can very effectively be used as a passive tracer (or indicator) of field variations. Indeed, its velocity over the last century very accurately indicates the geomagnetic impulses (or jerks) that were so far observed only in observatory data.
\end{abstract}

\section{Introduction}

The generic term "magnetic poles of the Earth" is sometimes used with different meaning corresponding to the type of analysis used to define them (see Fraser-Smith, 1987). In the following, we are interested in the magnetic dip poles, to which we will simply refer to as "magnetic poles". The magnetic pole positions are defined as the site where the field direction is vertical. The "modeled" magnetic dip poles are determined from a geomagnetic model obtained using ground or satellite data such as IGRF/DGRF (e.g. Mandea and Macmillan, 2000) or OIFM (Olsen et al., 2000). The "true" magnetic pole positions are obtained by a ground survey of a relevant polar region.

Because the dipolar field dominates, the Earth's field exhibits two magnetic poles only (located nearby the geographic poles). The decay time for the main dipole part of the geomagnetic field, whose constancy and simple geometry permits the use of magnetic compass, is estimated to be roughly 15,000 years. Paleomagnetic studies (e.g. Carlut et al., 2000) demonstrated that when averaged over such a long period of time the geomagnetic field is consistent with a pure axial dipole (i.e. the magnetic poles coincide with the geographic ones). On shorter time scale, the precise positions of these poles change with time around these equilibrium positions.

Surprisingly, the North Magnetic Pole (NMP) velocity has more than doubled in the last 30 years, reaching the huge velocity of around $40 \mathrm{~km} / \mathrm{year}$ in 2001 . Such velocity is the highest observed so far over the 20th century. This fact has been given much attention in recent research (Newitt et al., 2002), and together with the weakening of the Earth's magnetic field intensity over the last century has raised the

Copy right (C) The Society of Geomagnetism and Earth, Planetary and Space Sciences (SGEPSS); The Seismological Society of Japan; The Volcanological Society of Japan; The Geodetic Society of Japan; The Japanese Society for Planetary Sciences. concern of a possible approaching polarity reversal (Hulot et al., 2002). Nevertheless such an imminent reversal remains highly hypothetical; the Earth's dipole reverses direction only occasionally, generally a few times each million years.

\section{The Magnetic Poles \\ 2.1 Pole locations from direct measurements}

Seemingly random movements on the scale of $\mathrm{km}$ occur almost daily: the pole wanders in a roughly elliptical path around its average position, and may frequently be some 100 $\mathrm{km}$ away from this position, depending on the magnetic disturbances in the ionosphere and magnetosphere. In addition, the magnetic poles seem to also have had a generally northnorth-western drift over the last century. Close to the pole, an area is reached where the compass starts to behave erratically, and eventually, as the horizontal force decreases even more, the compass becomes unusable.

The first measurements to locate the magnetic poles are due to 19th century expeditions (Tables 1 and 2). The NMP was first located by Sir John Ross, in 1831, at Cape Adelaide on the west coast of Boothia Peninsula, where he measured a dip of $89^{\circ} 59^{\prime}$. Some 70 years later, Roald Amundsen made the next attempt to reach the NMP. The following observations were realized by Paul Serson and Jack Clark in 1947, and thereafter by scientists from Geological Survey of Canada. The most recent position of the NMP was obtained from measurements made by a Canadian-French team (Newitt et al., 2002). During this expedition, at each site, the direction of the magnetic field was measured using a declinometer-inclinometer magnetometer consisting of a single-axis fluxgate sensor, mounted on a non-magnetic theodolite. The theodolite was also used for Sun's observations, needed to determine the direction of the true north. A proton magnetometer gave the total intensity of the field.

Measurements of the South Magnetic Pole (SMP) position 
Table 1. North magnetic pole positions.

\begin{tabular}{llcl}
\hline 1831 & $70^{\circ} 05^{\prime} \mathrm{N}$ & $96^{\circ} 47^{\prime} \mathrm{W}$ & James Ross \\
1904 & $70^{\circ} 31^{\prime} \mathrm{N}$ & $96^{\circ} 34^{\prime} \mathrm{W}$ & Amundsen \\
1948 & $73^{\circ} 54^{\prime} \mathrm{N}$ & $100^{\circ} 54^{\prime} \mathrm{W}$ & Serson, Clark \\
1962 & $75^{\circ} 06^{\prime} \mathrm{N}$ & $100^{\circ} 48^{\prime} \mathrm{W}$ & Loomer, Dawson \\
1973 & $76^{\circ} 00^{\prime} \mathrm{N}$ & $100^{\circ} 36^{\prime} \mathrm{W}$ & Niblett, Charboneau \\
1984 & $77^{\circ} 00^{\prime} \mathrm{N}$ & $102^{\circ} 18^{\prime} \mathrm{W}$ & Newitt, Niblett \\
1994 & $78^{\circ} 18^{\prime} \mathrm{N}$ & $104^{\circ} 00^{\prime} \mathrm{W}$ & Newitt, Barton \\
2001 & $81^{\circ} 18^{\prime} \mathrm{N}$ & $110^{\circ} 48^{\prime} \mathrm{W}$ & Newitt, Mandea, McKee \\
\hline
\end{tabular}

Table 2. South magnetic pole positions ( $\sim$ marks an approximate measurement).

\begin{tabular}{lrrl}
\hline 1840 & $\sim 75^{\circ} 20^{\prime} \mathrm{S}$ & $\sim 132^{\circ} 20^{\prime} \mathrm{W}$ & Dumoulin, Coupvert \\
1840 & $\sim 71^{\circ} 55^{\prime} \mathrm{S}$ & $\sim 144^{\circ} 00^{\prime} \mathrm{W}$ & Wilkes \\
1841 & $\sim 75^{\circ} 05^{\prime} \mathrm{S}$ & $\sim 154^{\circ} 08^{\prime} \mathrm{W}$ & Ross \\
1899 & $\sim 72^{\circ} 40^{\prime} \mathrm{S}$ & $\sim 152^{\circ} 30^{\prime} \mathrm{W}$ & Bernacchi, Colbeck \\
1903 & $\sim 72^{\circ} 51^{\prime} \mathrm{S}$ & $\sim 156^{\circ} 25^{\prime} \mathrm{W}$ & Chetwynd \\
1909 & $72^{\circ} 25^{\prime} \mathrm{S}$ & $155^{\circ} 16^{\prime} \mathrm{W}$ & Mawson \\
1912 & $71^{\circ} 10^{\prime} \mathrm{S}$ & $150^{\circ} 45^{\prime} \mathrm{W}$ & Webb \\
1931 & $70^{\circ} 20^{\prime} \mathrm{S}$ & $149^{\circ} 00^{\prime} \mathrm{W}$ & Kennedy \\
1952 & $68^{\circ} 42^{\prime} \mathrm{S}$ & $143^{\circ} 00^{\prime} \mathrm{W}$ & Mayaud \\
1962 & $67^{\circ} 30^{\prime} \mathrm{S}$ & $140^{\circ} 00^{\prime} \mathrm{W}$ & Burrows, Hanley \\
1986 & $\sim 65^{\circ} 20^{\prime} \mathrm{S}$ & $\sim 139^{\circ} 10^{\prime} \mathrm{W}$ & Quilte, Barton \\
2000 & $64^{\circ} 40^{\prime} \mathrm{S}$ & $138^{\circ} 20^{\prime} \mathrm{W}$ & Barton \\
\hline
\end{tabular}

are also available since the 19th century (Table 2), although not all of these are accurate. Mawson made the first real determination of the SMP position in 1909. Some other measurements to locate the SMP were done by scientists from different countries, the most recent ones being those made in 2000 by Barton (2002).

Let us stress that the quality of magnetic measurements is not the same over centuries. In the following we concentrate on magnetic field modeling and magnetic pole positions over the 20 th century, only.

\subsection{Pole locations from main-field modeling}

The last years have also seen a new interest in using historical measurements of the geomagnetic field, to extent the period over which data are available and to better describe the field. Recently, Jackson et al. (2000) used data from 1590 onwards, derived primarily from observations made on commercial and naval ships, for mapping the global magnetic field back to the end of the 16th century. The model relies on marine data early in the period, then an increasing number of land measurements and finally some permanent observatory data. Using the Jackson et al. model, the positions of both magnetic poles are computed for each year between 1900 and 1990 (Fig. 1). The last two positions, for 2000 and 2001 are computed from Langlais et al. model (2003), based on Ørsted satellite data. These positions are to be compared with pole locations obtained from direct observations, as reported previously. Taking into account that the model was established without any magnetic data around the poles, the agreement is remarkable and provides a good a posteriori validation of the model. Because less measurements were available in the southern hemisphere, the model yields less accurate estimates of the SMP position.

The good agreement between models and observations of magnetic pole positions prompts us to construct a continuous variation of the pole velocities over the 20th century, based on the geomagnetic field model of Jackson et al. (2000). Figure 2 reveals that the recent SMP velocity is remarkably moderate and does not reflect the sudden increase noted in the NMP velocity (Newitt et al., 2002).

Taking into account the recent magnetic pole positions highlights even more clearly this different behavior. The ground measurements made in 2000 to locate the SMP (Barton, 2002) and 2001 to locate the NMP (Newitt et al., 2002) clearly underline this discrepancy. Moreover, the pole positions obtained from models derived using Ørsted satellite data (for epochs 2000 and 2001) are nearly identical for the SMP $(64.28 S, 138.05 E$ in 2000 , and $64.26 S, 137.98 E$ in 2001), but differ by more than a degree for the NMP $(81.12 N, 110.48 \mathrm{~W}$ in 2000 , and $81.54 N, 111.80 \mathrm{~W}$ in 2001). These measurements yield the dashed line trends on Fig. 2, corresponding to a velocity of about $52 \mathrm{~km} /$ year for the NMP and some $4 \mathrm{~km} /$ year for the SMP. This demonstrates a clear asymmetry in the poles behavior. 

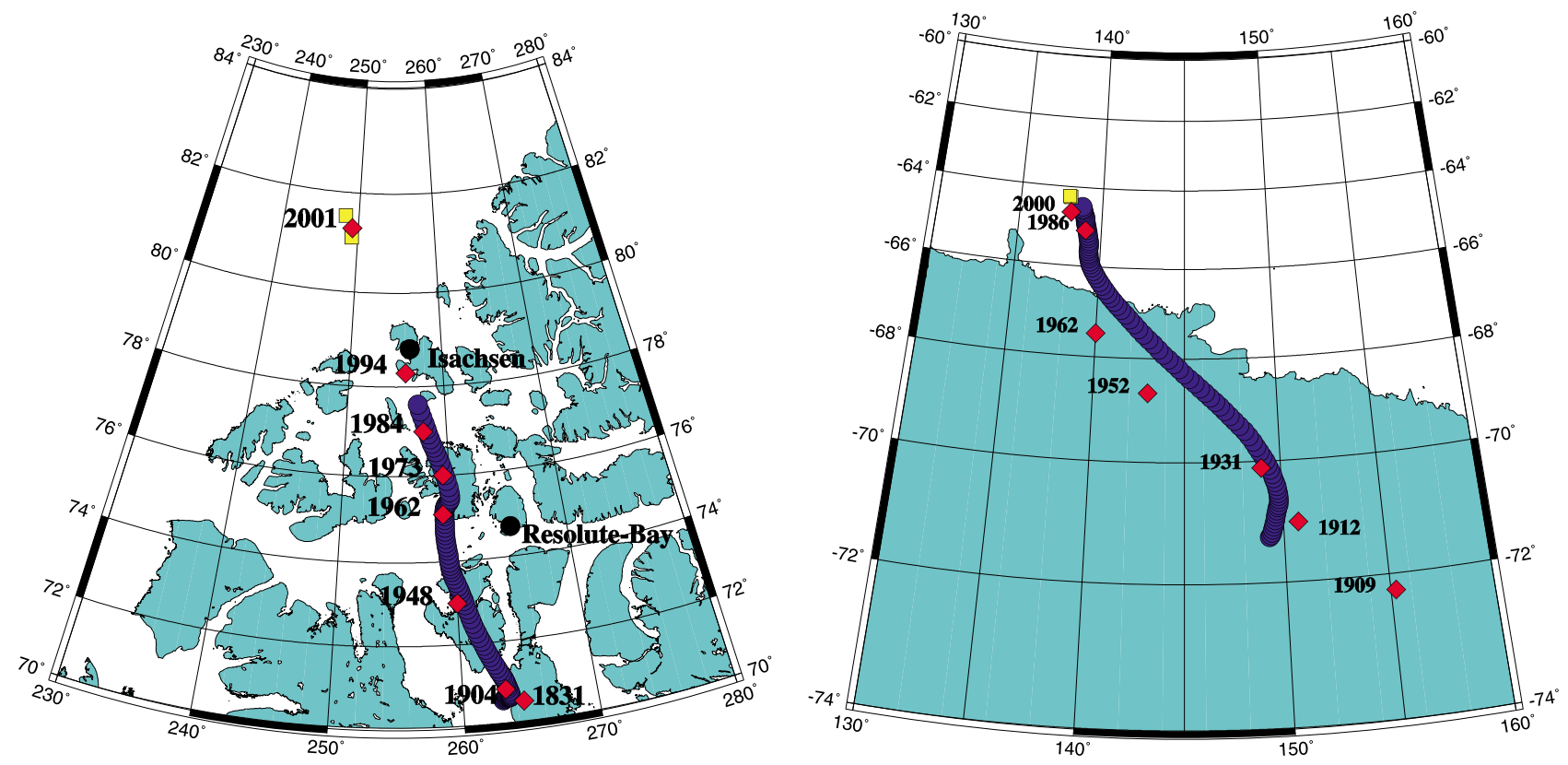

Fig. 1. North and south magnetic pole locations: from direct measurements (red diamonds); from Jackson et al. model (blue circles); from Langlais et al. (yellow squares).

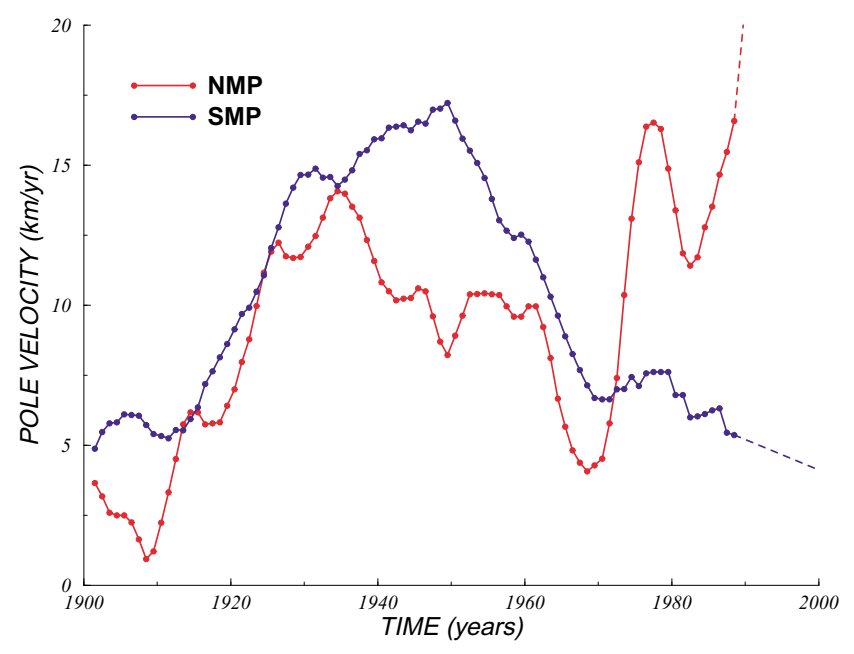

Fig. 2. North and south magnetic pole velocities computed from a geomagnetic field model over the 1900 to 1990 period (Jackson et al., 2000). The dashed lines show the linear trend from 1990 to 2001, this last value being computed from Langlais et al. model (2003).

\section{The North-South Asymmetry}

Better understanding of this behavior can be achieved by direct representation of the horizontal component of the field $\left(B_{H}\right)$ from the main-field model $\left(B_{H}=\sqrt{X^{2}+Y^{2}}\right.$, where $X$ and $Y$ are the northward and eastward components). Such representation has been used in the past for the NMP (Hope, 1957). Figure 3 shows that $B_{H}$ exhibits a very flat gradient in the direction of the pole motion, for the NMP. However, $B_{H}$ has a sharper and more isotropic gradient for the SMP. As a result, small variations in the field can yield important displacement of the NMP, making the NMP position an illdefined quantity. Indeed, whereas the NMP position was varying rather significantly over the last century, the maps of Fig. 3 barely show any sign of variation. The SMP position, however, is rather well constrained and is barely affected by small amplitude variations of the field.

This description implies that the NMP is bound to stay in the area characterised by weak $B_{H}$ intensity, pending the slow variation of the main field morphology. Relying on the present field morphology, the NMP is thus rather free to move, subject to small variations of the field, while the SMP position is only affected by significant variations of the main field. This remark makes the NMP position a candidate for tracing rapid and small changes in the main field, such as sudden changes in the secular variation.

\section{Geomagnetic Jerks and Impulses in the NMP Velocity}

The identification of an abrupt change in the trend of the geomagnetic secular variation, referred to as a "geomagnetic jerk" (Courtillot et al., 1978; Malin et al., 1983), and the demonstration that they really are of internal origin, required some effort in the last few years (to characterise the date at which they occur, their time duration, and their worldwide character). Examination of geomagnetic data from worldwide observatories has indeed revealed that a series of "geomagnetic jerks" or "secular variation impulses" occurred during the 20th century. Three of these events (1969, 1978, 1991) are unquestionably of global extent (Alexandrescu et al., 1996; Le Huy et al., 1998; Nagao et al., 2002). Three events $(1901,1913,1925)$ are possibly of similar extent (but worldwide data are not available for the beginning of the century), while two of these (1932 and 1949) are not reported everywhere at the Earth's surface (Alexandrescu et al., 1996).

In order to illustrate these events, we present the secular variation at the Niemegk (NGK) observatory, which has a central position in Europe. Figure 4 represents the secular variation for the East component of the field at NGK, together with the NMP velocity as derived from the model proposed by Jackson et al., (2000). The dates of four jerks, 
1960
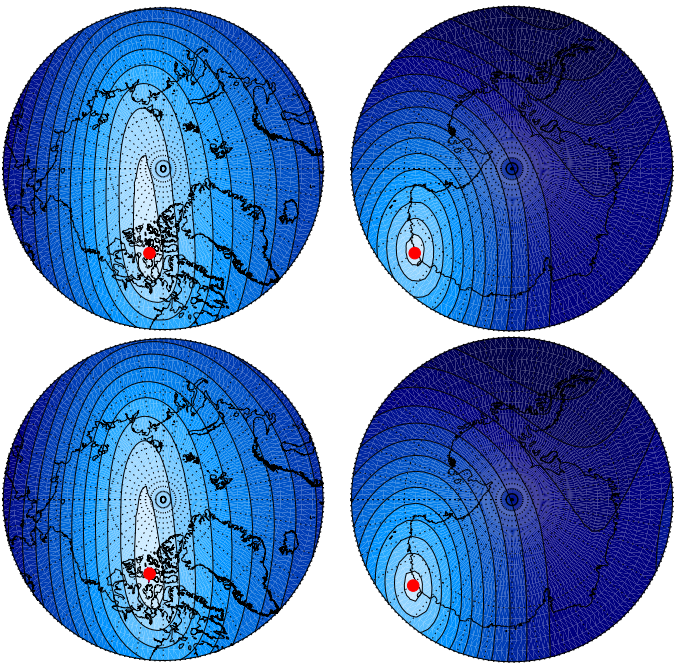

1970

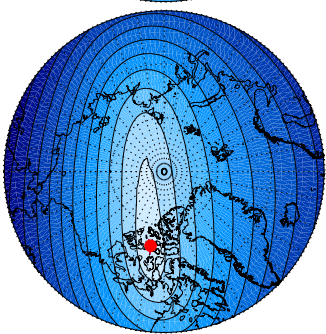

1980
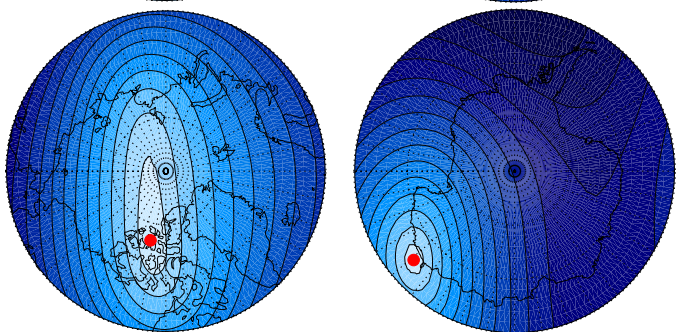

1990
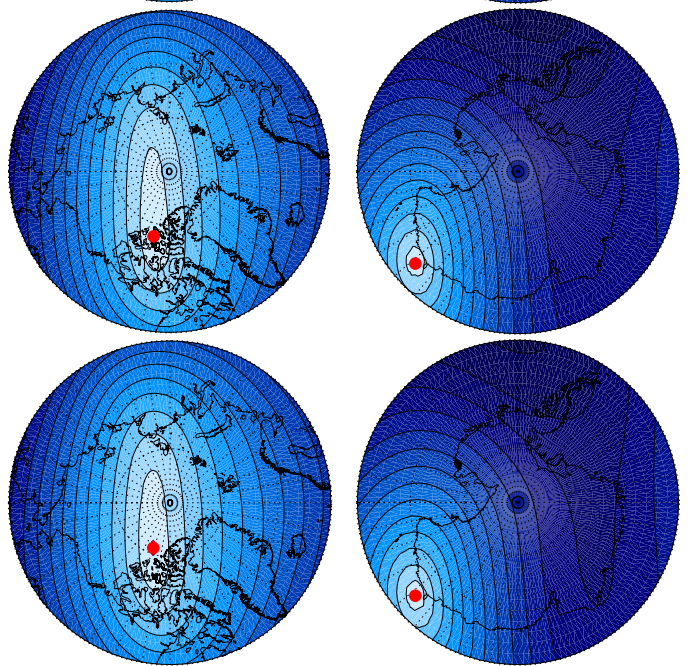

Fig. 3. Isovalues of the $L_{2}$ norm of the horizontal component of the magnetic field (i.e. $\sqrt{X^{2}+Y^{2}}$, see text for more details) in the high-latitude areas (using the Jackson et al. model for the period 1960-1990 and the Langlais et al. model for 2000); deeper blue indicates larger modulus, contour interval is $1500 \mathrm{nT}$. The approximate position of the poles are indicated by the red dots.

well defined by NGK data and the Jackson et al. model are indicated $(1913,1925,1969,1978)$. Clearly the NMP velocity is affected by each of these jerks: a local extremum in the NMP coincides with a jerk. Of course, the NMP also evolves under some other influences, describing its secular motion, and this also induces some extrema which are not necessarily correlated with jerks.

Let us note that the high-quality results on describing the geomagnetic jerks have been possible only recently, with the availability of accurate magnetic observatory data. Without doubt, one of the most crucial needs for understanding these events is to ensure that data are gathered from well dis-

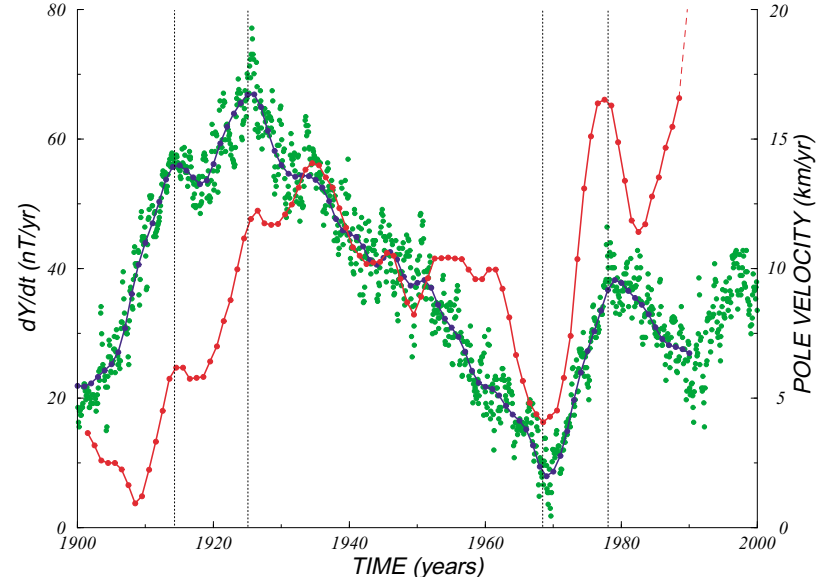

Fig. 4. Geomagnetic impulses are usually observed taking the derivative of the East magnetic component at a fixed location (here at the NGK observatory-green dots, left scale). The same quantity can be derived for the same location using a main-field model (here Jackson et al.-blue curve, left scale). The dates of four jerks (1913, 1925, 1969, 1978), well defined by NGK data and the Jackson et al. model, are indicated by vertical dotted lines. For comparison, the NMP velocity (red curve) is represented as on Fig.2 (right scale).

tributed permanent magnetic observatories and/or satellites (if a geomagnetic jerk would occur during a space mission). In this light, Fig. 4 shows strong evidence that the NMP velocity is related to geomagnetic jerks, confirming the influence of jerks on another type of measurement. In addition, these correlations at the NMP with other observatories may provide details of the spatial extent of the event and may provide clues into the dynamics of its origin.

\section{Conclusions}

In the present study, we took advantage of both new measurements of magnetic dip pole positions (Barton, 2002; Newitt et al., 2002), and a recent geomagnetic field model proposed by Jackson et al. (2000). Combining these information, we clearly showed the different behavior of both poles over the last century and explained how this stems from the field geometry near the poles over this period. The close agreement between the measurements and the field model allowed us to confidently derive the time evolution of both pole velocities. This demonstrated that the NMP position is very sensitive to small changes in the field. Its velocity is thus significantly affected by consecutive geomagnetic jerks over the last century.

Acknowledgments. We appreciate the dedicated work of people carrying out magnetic pole surveys. We acknowledge Larry Newitt for constructive discussions. We also would like to thank Hiromichi Nagao and Terence Sabaka for useful suggestions. This is IPGP contribution \#1886.

\section{References}

Alexandrescu, M., D. Gibert, G. Hulot, J.-L. Le Mouël, and G. Saracco, Worldwide analysis of geomagnetic jerks, J. Geophys. Res., 101, 21975 21994, 1996.

Barton, C., Survey Tracks Current Position of South Magnetic pole, EOS, 83(27), 291, 2002.

Carlut, J., V. Courtillot, and G. Hulot, Over how much time should the geomagnetic field be averaged to obtain the mean paleomagnetic field? Terra Nova, 11(5), 239-243, 2000. 
Courtillot, V., J. Ducruix, and J.-L. Le Mouël, Sur une accélération récente de la variation séculaire du champ magnétique terrestre, C. R. Acad. Sci. D, 287, 1095-1098, 1978.

Fraser-Smith, A. C., Centered and eccentric geomagnetic dipoles and their poles, 1600-1985, Rev. Geophys., 25, 1-16, 1987.

Hope, E. R., Linear secular oscillation of the northern magnetic pole, $J$. Geophys. Res., 62-1, 19-27, 1957.

Hulot, G., C. Eymin, B. Langlais, M. Mandea, and N. Olsen, Small-scale structure of the geodynamo inferred from Oersted and Magsat satellite data, Nature, 416, 620-623, 2002.

Jackson, A., A. Jonkers, and M. Walker, Four centuries of geomagnetic secular variation from historical records, Phil. Trans. R. Soc. Lond., 358, 957-990, 2000.

Langlais, B., M. Mandea, and P. Ultré-Guérard, High-resolution magnetic field modeling: application to MAGSAT and Ørsted data, Phys. Earth Planet. Int., 2003 (in press).

Le Huy, M., M. Alexandrescu, G. Hulot, and J.-L. Le Mouël, On the characteristics of successive geomagnetic jerks, Earth Planets Space, 50, 723-732, 1998.

Malin, S. R. C., B. H. Hodder, and D. R. Barraclough, Geomagnetic secular variation: A jerk in 1970, in 75th Anniversary Volume of Ebro Observa- tory, edited by J.O. Cardus, pp. 239-256, Roquetes, Tarragona, Spain, 1983.

Mandea, M. and S. Macmillan, International Geomagnetic Reference Field-The Eighth Generation, Earth Planets Space, 52, 1119-1124, 2000.

Nagao, H., T. Iyemori, T. Higuchi, S. Nakano, and T. Araki, Local time features of geomagnetic jerks, Earth Planets Space, 54, 119-131, 2002.

Newitt, L. R., M. Mandea, L. A. McKee, and J.-J. Orgeval, Recent acceleration of the North Magnetic Pole linked to magnetic jerks, EOS, 83, 381-388, 2002.

Olsen, N., R. Holme, G. Hulot, T. Sabaka, T. Neubert, L. Toeffner-Clausen, F. Primdahl, J. Joergensen, J.-M. Leger, D. Barraclough, J. Bloxham, J. Cain, C. Constable, V. Golovkov, A. Jackson, P. Kotze, B. Langlais, S. Macmillan, M. Mandea, J. Merayo, L. Newitt, M. Purucker, T. Risbo, M. Stampe, A. Thomson, and C. Voorhies, Oersted Initial Field Model (OIFM), Geophys. Res. Lett., 27(22), 3607-3610, 2000.

M. Mandea (e-mail: mioara@ipgp.jussieu.fr) and E. Dormy (e-mail: dormy@ipgp.jussieu.fr) 